\title{
Does Profitability affect Debt Ratio? Evidence from Vietnam Listed Firms
}

\author{
Nguyen Tra Ngoc Vy*
}

\begin{abstract}
The main objective of this study is to examine the relationship between profitability and leverage of Vietnam listed corporations in the aftermath of the Global Financial Crisis (GFC). The study finds strong evidence that this relationship is negative. This conclusion is not affected by control variables as well as firm and year fixed effects. Particularly, it is found that the smaller the firms are, the more profound the relationship is. In line with many previous researches, this result is in favor of the Pecking order theory. In the Vietnamese context, small and profitable firms tend to have higher incentive to use less debt. In contrast, large firms seem to be indifferent in their debt use due to having greater access to other sources of finance, as well as a larger base of collateral assets. Interestingly, in stark contrast to the arguments made in official economic reports as well as the common consensus, Vietnam's firms operating in building and property industries do not borrow more than other firms, even after the GFC when the government released its rescue package.
\end{abstract}

Keywords: Financial leverage, profitability, firm-fixed effect, pecking order, static trade-off

\section{Introduction}

An impressive body of research has been done on the effect of profitability on financial leverage, as well as trying to find the explanation for corporate capital structure choices of firms in different countries and different economic environments. I can track the beginning of this arguably most influential branch of financial research from the seminal work of Modigliani and Miller (1958) who propose the theory of irrelevance (now famously known as M\&M theorem). These authors argue that, given a non-tax environment, the market value of a firm is determined by its earning power and the risk of its underlying assets. Thus, firm value is not determined by how they choose to finance their investments and distribute their dividends. In other words, there is no difference in firm value whether a firm finances itself by debts or equities. M\&M then suggests that only a firm's productivity determines a firm's value. Going a step further, Miller and Modigliani (1961) relaxed the assumption of no taxing and reconsidered the value of corporate tax shield. It is proved that debt financing will help to increase value of the firm.

By the end of the 1990s, determinants of capital structure had been extensively studied with considerations to various market frictions such as agency cost, information asymmetry, taxes and different types of transaction costs. The early studies are generalized into the so-called Trade-Off theory, which was first proposed by Kraus and Litzenberger (1973). This theory suggests that managers can achieve the optimal capital structure base on a trade-off of the costs and benefits

\footnotetext{
*Faculty of Economics and Accounting, Quy Nhon University, Binh Dinh, Vietnam. Yuan Ze University,

Taiwan. E-mail: ngocvy@qnu.edu.vn
} 
of borrowing. In other words, an optimal capital structure is a result of balancing the value of interest tax shields against the various costs of bankruptcy and financial distress. Titman (1984) also indicates that although debt financing gives the firm the tax shield advantage, an excess use of debt also increases the risk of bankruptcy. Under the Trade-Off theory, it is predicted that there is a positive relationship between profitability and leverage of the firm. This is because profitable firms will most likely try to use more debt financing to maximize their interest tax shield (Barclay \& Smith, 1999). Furthermore, large, profitable firms are more stable, have less volatile cash flows and low information asymmetry, all of which make it easier to obtain external financial resources compared with small firms. Along this line is the work of (Munene, 2006). He conducted his research on firms listed on the Nairobi stock exchange from the period 1999-2004 and showed a weak positive relationship between profitability and capital structure of firms.

It can be seen that the original Trade-Off theory can explain the difference in the capital structures among industries due to different asset structures, however, in some cases, it cannot explain the relationship between high profitability ratio and low leverage ratio. A firm with high profitability ratio should be more likely to adopt a higher debt ratio to exploit the benefit of tax shield, but in reality many companies with high profitability ratio have a tendency to reduce their debt ratio. To partly explain this tendency, we consider the Pecking Order theory.

The Pecking Order theory (Myers, 1984) states that firms have a preference for using internally available funds first (i.e. retained earnings), followed by debt and external capital, to finance their activities. While choosing between debt and external equity financing, a firm prefers less informative costly sources over the costlier ones. Contrary to the Trade-Off theory, the Pecking Order theory posits the negative relation between profitability and leverage. This theory suggests that highly profitable firms prioritize their investments with internal finance to reduce the transaction costs relating to asymmetric information between insiders and outsiders. Hamilton and Fox (1998) show that managers prefer to use the retained earnings to finance their project to the equity as they do not want to share their control of company with outsiders. Baskin (1989) also found that the cost for issuing equity is larger than cost for raising debt. Therefore, external equity is always regarded as the last choice for raising finance from the perspective of Pecking Order theory.

Empirical evidence supporting the negative relationship between profitability and leverage is in favor of the Pecking Order theory. Gaud, Jani, Hoesli, and Bender (2005) suggest that profitable firms prefer using internal financing, while low profit firms tend to rely heavily on debt due to their volatile cash flows and limited ability to access the equity capital market. Extending this idea, Rajan and Zingales (1995) used four key independent variables including market-to-book ratio, firm size, profitability, and tangibility of assets, to analyze the determinants of capital structures. They showed a negative relationship between growth and leverage, and tangibility is always positively correlated with leverage across the firms in G-7 countries. Booth, Aivazian, Demirguc-Kunt, and Maksimovic (2001) studied capital structure choices of firms in 10 developing countries, and provided further evidence of the negative relationship between profitability and leverage. Chen (2004) used trade-off model and the pecking order hypothesis to determine the variables influencing capital structure of listed firms including profitability, size, growth opportunities, asset structure, cost of financial distress, and tax shield effects. The results indicated that profitability and firm size have a negative relationship with debt, while growth opportunities and tangibility have positive relationship with debt. Furthermore, this study also highlighted a remarkable difference between the capital choices of Chinese firms and firms in developed economies: Chinese firms prefer short-term debt to long-term debt. Similarly, Wanrapee (2011) used 81 listed companies in Thailand to show that profitability and tangibility have a significantly negative relationship with leverage, while size positively affects leverage. Additional evidence consistent with the Pecking Order theory on the basis of a negative relation between these two variables could be found in 
studies such as (Qureshi, 2009; Akdal, 2011; Ozkan, 2001; Serrasqueiro \& Nunes, 2010).

Furthermore, many previous studies also displayed the concern in the relationship between firm size and profitability. Some results showed that the effect of size on long run leverage is quite ambiguous. Large firms often have more competitiveness and bigger market share than small ones, thus they tend to have more opportunities to make profit and invest in more profitable projects. Rajan and Zingales (1995) found that large firms are more diversified and have a lower bankruptcy risk and easier access to debt market. Hol and Wijst (2006) studied of Norwegian non-listed firms and found that size is one of the proxies determining the corporate financial structure. Saliha and Abdessatar (2011) also suggest that firm size positively affects profitability. In contrast, Banchuenvijit (2012) points out there is a negative relationship between firm size and profitability. Panno (2003) and Ojah and Manrique (2005) also suggest the same result. Different from above studies, Whittington (1980) indicated that there is no relationship between firm size and profitability. It is apparent that size is also a proxy for information asymmetry, and large firms with lower information asymmetry will acquire greater advantage in issuing equity.

In the context of Vietnam recently, T. K. T. Le (2012) studied the factors influencing capital structure of real estate companies listed on Ho Chi Minh Securities Exchange (HOSE) from 2007 to 2011. The results show that firm size, profitability and tangibility have a negative relationship with capital structure, while growth positively relates to capital structure. Along this line, D. C. Le (2013) implemented tests to examine the important factors in capital structure of listed companies from 2007 to 2010. The results indicated six important variables including tax, inflation, marketto-book ratio, industry leverage, profitability, and managerial behavior. The author also found evidence supporting the pecking order theory, while there is little consistence with the trade-off theory.

In the recent context of Vietnam, Nhung and Okuda (2015) investigated the capital structure and profitability of the companies listed on HOSE and the Hanoi Stock Exchange (HASE) in Vietnam by estimating their debt ratios and return rates using the three-stage least squares method. These authors found that capital structures of the listed companies matched the corporate financing theories better than those of small- and medium-sized firms. Additionally, weak corporate governance due to insufficient monitoring by creditor led the listed companies to borrow excessively in the periods before and after the boom. The state-controlled companies listed on the HOSE are likely to have much less financial constraints than private firms, even after the boom period. Holding other corporate characteristics constant, Nguyen and Nguyen (2015) confirm a significant negative impact of leverage on firm's performance, regardless of debt maturity. A general consensus is that Vietnam emerging stock exchange seems to exhibit traits in agreement with most well-established theories in the capital structure literature.

The data scope of our paper (with over 200 firms from 9 industries over a period of 5 years, for a total of 1238 firm-year observations) generally exceeds most of similar studies on Vietnam's listed firms, thus giving us a strong position to present more rigorous empirical evidence. Another shortfall of previous researches is that they primarily studied the impact of capital structure on firm performance, rather than the other way around. More importantly, these papers do not focus on examining industry effect on finance structure of the firms with respect to the major Vietnamese economic sectors which comprise both state-owned and private companies, thus leaving a research gap which will be partly addressed in this study.

\section{Motivations and Research Significance}

Many studies on the influence of profitability on leverage in both developed and emerging countries have been conducted during the last two decades. Nevertheless, I, believe there is currently limited 
rigorous research with respect to the impact of firm size and industry sector on the relationship between the profitability and leverage in the Vietnamese context, especially for the debt-riddance property section during and after the Global financial crisis in 2008. The need for such an analysis grows stronger than ever, as a result of the recent turbulent public debt distress and sector-wide financial restructuring Vietnam is experiencing. The gap between how profitable firms choose to finance in theory and in practice needs to be understood by the academics, if any hope for successful restructuring is to be expected. My study aims to partly close this gap by rigorously investigating this particular linkage. Additionally, I take firm size and industry sector as moderators to clarify whether they create any changes in the relationship between profitability and leverage. Using data from Vietnam's market contributor to lay some groundwork upon which a more detailed evaluation can be made available for policy makers, corporate managers, and investors in other developing markets.

\section{Potential Policy Implications}

For an emerging economy like Vietnam, investments in the land and property sector play an indispensable role in its steady and fast GDP growth rate, which is estimated to be about $7 \%$ in the last decade (International Monetary Fund, 2016). But it is also considered by many to be the main factor behind the general financial instability and bad debts that currently plague Vietnam's fragile banking industry. So far the merit of such an argument has not been investigated by rigorous research. Various official economic reports focusing on the aftermath of the GFC also advocate this observation (International Monetary Fund, 2016). Given the complex and the strong linkage between this sector's performance and government fiscal policies, it will be instructive to look deeper into the impact the finance structure of these firms have on their profitability in particular, and on the economy's overall performance in general.

With respect to Vietnam's property market throughout the last two decades, we can generally categorize three states of development which exhibit clear trending behavior in accordance with the historical legislative movements into the following three periods:

-First period: post-Doi Moi growth spurt from 1991 to late 1996 followed by a slow-down in 1997-1999. The former was slimulated by the government's market-to-market pricing mechanism, while the later was a result of the Asian financial crisis coupled with the stricter government property controls.

-Second period: the 2000-2004 growth with the world economic recovery and the introduction of the tax reform acts at the time. This was interrupted by the speculation on the effect of newly introduced Lands Law in 2003. From 2004, the operation of stock market and privatization wave attracted a substantial number of investors from property into stocks. The stock bubble burst in 2007 revived interest in property investment.

-Third period: the fast growth in 2007 and early 2008, was followed by prolonged depression dressed up with periodic price adjustments which has continued since then. Mimicking the behavior of the U.S. market, property sales and foreign influx of capitals went hand-in-hand in this 'golden era' when prices kept soaring for all property types. Most firms in this period borrowed heavily to finance their projects. Not long after this period, the full impact of the Global Financial Crisis (GFC) washed over this sector. It worsened the overconfidence that was the market norm at the time, and the government spending and banking credit were both slashed to a critical level, leaving the sector in a stagnation state and virtually nullifying the sales.

Fortunately, a life-saving major government stimulus (estimated to be more than 30000 billions VND VNeconomy (2015) was plumped to help restore some of the market confidence. However, the fund was mostly absorbed by the luxury properties segment, while projects for the middle- 
income customers were generally neglected. Overinvestment in luxury projects and inflated pricing eventually lead to a serial collapse of about one half of the sector's firms. The government stimulus was not sustained for very long, and in 2011, credit slashing again brought about even slower growth for the sector. In conclusion, there is a broad consensus, which is supposed to corroborate with these empirical observations, that it is the extending borrowing of these firms that lead to their down fall in late 2008. Our argument in the latter sections shows that this is not the case.

Vietnam's property sector, like that of other emerging countries, suffers greatly from the procyclical development states. In many senses it is also not different from the fiasco experienced by developed market. Fast, "hot" growth is followed by a prolonged episode of depression and then "hard landing". This process raises some pertinent questions: How much of this process is accelerated by the property companies' debt financing behavior? Is it true that the financial structure of these firms statistically different from firms in other sectors? These are among the questions that I seek answers in this study. To offer-updated insights, I have focused on the most recent period after the Global financial crisis (GFC). Interestingly, among many important implications, I find that Vietnam's firms operating in building and property industries do not seem to borrow significantly more than other industries, even during the aftermath of the GFC when the government released its rescue package. This observation generally goes against the arguments made in official economic reports at the time,

\section{Research Questions and Statistical Hypotheses}

\section{Research Questions}

In the present study, I specifically address the following questions:

Q1: Do firm-specific factors, particularly profitability, correlate with the leverage and have the same influence (in terms of sign and magnitude) on leverage in Vietnam as predicted by established theories and suggested by previous studies?

Q2: Will this relationship change when controlling for industry?

Q3: Does this relationship differ significantly between firms of different sizes?

In light of the literature reviewed above, I will develop and test the following hypotheses:

\section{Hypotheses}

H1a: There is a significantly negative relation between profitability and leverage.

H1b: There is a significantly positive relation between profitability and leverage.

H2a: The relation between profitability and leverage is significant among small firms.

H2b: The relation between profitability and leverage is significant among large firms. 


\section{Data Description and Preliminary Examination}

The data were gathered by the author from financial statements of all listed firms on Ho Chi Minh Stock Exchange (HOSE) in Vietnam during the period 2009 - 2013. I eliminated financial firms such as banks and insurance companies from the sample due to their unique capital structures and the different meaning of financial leverage in these firms. As a result, the final sample set consists of over 200 firms from 9 industries over a period of 5 years, for a total of 1238 firm-year observations. This is an unbalanced panel since not all firms have data in all years.

I formed the following three groups by dividing firms on the basis of size (size is proxied by annual sale value) I have:

- Group 1: included firms with firm size $<300$ billions VND

- Group 2: included firms with firm size from 300 to 1.000 billions VND

- Group 3: included firms with firm size $>1.000$ billions VND

Table 1

Definition of explanatory variables

\begin{tabular}{lll}
\hline Variable names & Variable notations & Definition \\
\hline Leverage & leverage & Ratio of book value of total debt to total assets \\
Firm size & logsale & Logarithm of net sale \\
Market to Book & MTB & Ratio of market capitalization to book value \\
Profitability & Profitability & $\begin{array}{l}\text { Ratio of Earnings before interest, tax, and } \\
\text { depreciation and amortization (EBITD) to total assets }\end{array}$ \\
Tangibility & Tangibility & Ratio of fixed assets to the book value of total assets \\
\hline
\end{tabular}

To examine the data, the following analyses were done. Table 1 describes the formulation of our variables, following some of the most standard definitions in the literature. (See the Appendix for details). The descriptive statistics of the data are presented in table 2. I can see that of these variables, leverage and sale seem to be distributed reasonably close to symmetry, meaning their values are concentrated around the mean. On the contrary, tangibility and market to book ratio only have non-zero values and are skewed to the right (having long right tail) meaning the extreme positive values are more common compared with a normal distribution. All variables are leptokurtic, thus they have reduced possibility of tail values.

Table 2

Descriptive Statistics of explanatory variables

\begin{tabular}{lccccccc}
\hline Variable & Mean & Std. Dev. & Min & Max & Kurtosis & Skewness & Obs. \\
\hline Tangibility & 0.219 & 1.073 & 0.003 & 37.200 & 1146.200 & 33.200 & \\
Mtb & 1.055 & 0.989 & 0.014 & 12.700 & 35.900 & 4.300 & \\
Logsale & 13.160 & 1.591 & 6.200 & 18.040 & 4.060 & -0.500 & 1238 \\
Profitability & 0.591 & 2.654 & -15.800 & 29.900 & 43.400 & 4.600 & \\
Leverage & 0.491 & 0.208 & 0.002 & 0.980 & 2.100 & -0.200 & \\
\hline
\end{tabular}

The Pearson's correlation coefficient matrix reported in table 3 shows the correlation between variables and the corresponding p-values. From this table, the relationship between leverage and profitability is negative. Control variables show expected negative relationship with leverage except MTB variable. Although most of the pair-wise correlation coefficients are significant, none of these are economically importance, with a magnitude smaller than $25 \%$. This means it is highly 
unlikely for multi-collinearity to exist in our model, a fact that is confirmed by formal Variance Inflation Factor (VIF) test presented in Table 4. It can see that there is no correlation between the variables in regression model as the values of VIF in all variables are very small (or have very high tolerance values).

Table 3

Pearson correlation coefficient matrix for explanatory variables

\begin{tabular}{lcccc}
\hline & leverage & profitability & logsale & MTB \\
\hline Profitability & -0.160 & & & \\
& $(0.000)$ & & & \\
Logsale & 0.240 & -0.001 & & \\
& $(0.000)$ & $(0.9659)$ & & \\
MTB & -0.050 & 0.130 & 0.160 & \\
& $(0.073)$ & $(0.000)$ & $(0.000)$ & \\
Tangibility & -0.002 & 0.009 & 0.060 & 0.070 \\
& $(0.928)$ & $(0.765)$ & $(0.031)$ & $(0.008)$ \\
\hline Notes: p-values are in parentheses.
\end{tabular}

Table 4

Multi-collinearity test

\begin{tabular}{lcccc}
\hline & VIF & SQRT VIF & Tolerance & R-Squared \\
\hline Leverage & 1.100 & 1.050 & 0.909 & 0.091 \\
Profitability & 1.040 & 1.020 & 0.960 & 0.040 \\
Logsale & 1.100 & 1.050 & 0.908 & 0.092 \\
MTB & 1.050 & 1.030 & 0.950 & 0.050 \\
Tangibility & 1.010 & 1.000 & 0.992 & 0.008 \\
\hline Mean VIF 1.06 \\
Notes: VIF $>10$ indicates potential multi-collinearity. \\
\hline
\end{tabular}

To visualize the relationship between the explanatory variables and the dependent variable, the pairwise scatter plots are shown in Figure 1, 2, 3 and 4. There are some important notes that could be made from these plots:

- Figure 1: the majority of the firm-years have positive profitability and low leverage. Highly profitable firms, which have earning to asset ratio at around $15-30 \%$, mostly have a leverage of about 0.2 to 0.4 . In contrast, highly leveraged firms ( 0.6 to 0.98 ) tend to yield very low profits (earning rate is around 0 to $5 \%$ ) and in some cases, even yield losses (on average a 10\% loss). Overall, I can see a clear pattern of negative relation between profitability and leverage.

- Figure 2: Most of the Vietnam firms exhibit an MTB ratio of 5 or lower. This is the typical characteristic of small firms with high growth potential in developing markets whose market values are several (5) times greater than their book values. There is no notable asymmetry in the distribution of leverage among these firms: both high and low leverage levels are observed with fairly equal probabilities (although more concentration is at the mean leverage, around 0.5).

- Figure 3: The relationship between leverage and tangibility is quite similar to that between leverage and MTB ratio: no clear asymmetric pattern is observed between high and low leveraged firms. The overall level of tangibility of Vietnam firms is low.

- Figure 4: Among the four explanatory variables, size exhibits the clearest positive relationship with leverage: I can see that the change of size is accompanied by a proportional change of leverage. Intuitively, this means large Vietnam firms tend to borrow more. In section 7 I will consider the relationship of leverage and profitability with consideration to firm size. 


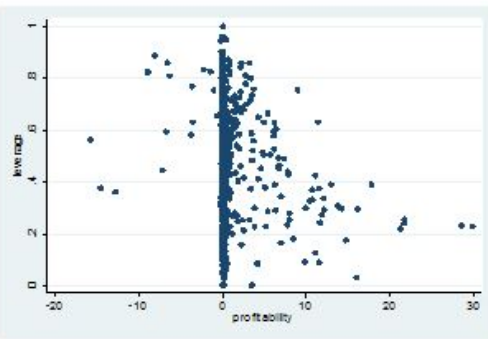

Figure 1

Scatter plot of leverage and profitability

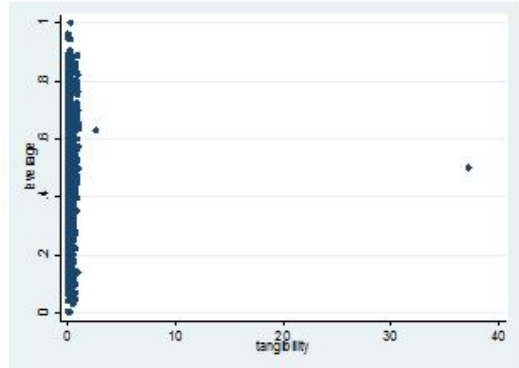

Figure 3

Scatter plot of leverage and profitability

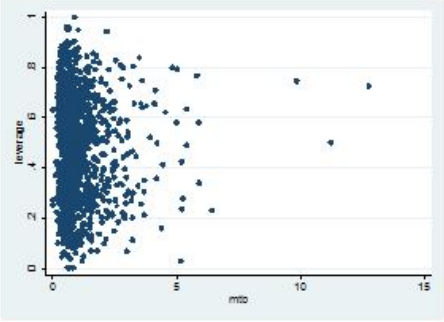

Figure 2

Scatter plot of leverage and market to book ratio

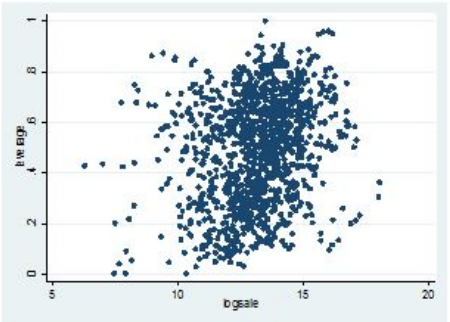

Figure 4

Scatter plot of leverage and market to book ratio

The following section discusses further preliminary examination of these pairwise relationships. When dividing the sample into 5 groups based on quintiles of profitability (pooling observations across firm-years), I can examine the statistical difference of the mean of other variables between the quintiles. Specifically, Table 5 shows that in terms of leverage, the group with lowest profitability exhibits a mean leverage of 0.60 , while the mean of the highest profitable group is 0.42 , with a significant difference of 0.176 . This means that on average, firms with highest profit level tend to use $17.6 \%$ less debt than firms that earn the lowest level of profit. Evidence supporting the arguments made with the above plots can be similarly derived for other variables.

Table 5

Differences in mean of the variables between the least and the most profitable firms

\begin{tabular}{lcccrrr}
\hline Variables & $\begin{array}{c}\text { Number of } \\
\text { Observation- } \\
\text { Lowest } \\
\text { Profitability }\end{array}$ & $\begin{array}{c}\text { Mean-Lowest } \\
\text { Profitability }\end{array}$ & $\begin{array}{c}\text { Number of } \\
\text { Observation- } \\
\text { Highest } \\
\text { Profitability }\end{array}$ & $\begin{array}{c}\text { Mean-Highest } \\
\text { Profitability }\end{array}$ & $\begin{array}{r}\text { Difference } \\
\text { in Mean }\end{array}$ & t-statistics \\
\hline Leverage & 248 & 0.60 & 247 & 0.420 & 0.176 & $9.481^{* * *}$ \\
logsale & 248 & 12.95 & 247 & 12.450 & 0.495 & $3.050^{* * *}$ \\
MTB & 248 & 0.60 & 247 & 1.240 & 0.064 & $9.921^{* * *}$ \\
Tangibility & 248 & 0.19 & 247 & 0.340 & -0.149 & -0.987 \\
\hline
\end{tabular}

Notes: *** denotes significance at the $1 \%$ level. 


\section{Research Method Description}

I applied the traditional (static) panel regression techniques including pooled Ordinary Least Squares where observations are stacked regardless of firms or years, Fixed-effect accounting for unobserved firm characteristics that are not captured by explained variables (which could create omitted variable bias) and Random-effect which presumes random relation between these characteristics and explained variables. These specifications are described as follows:

\section{Pooled OLS:}

$$
\text { Leverage }_{i t}=\beta_{o}+\beta_{1} \text { Logsale }_{i t}+\beta_{2} M T B_{i t}+\beta_{3} \text { Profitability }_{i t}+\beta_{4} \text { Tangibility }_{i t}+\mu_{i t}
$$

\section{Fixed effect model:}

$$
\text { Leverage }_{i t}=\beta_{o}+\beta_{1} \text { Logsale }_{i t}+\beta_{2} M T B_{i t}+\beta_{3} \text { Profitability }_{i t}+\beta_{4} \text { Tangibility }_{i t}+\mu_{i t}
$$

\section{Random effect model:}

$$
\text { Leverage }_{i t}=\beta_{o}+\beta_{1} \text { Logsale }_{i t}+\beta_{2} M T B_{i t}+\beta_{3} \text { Profitability }_{i t}+\beta_{4} \text { Tangibility }_{i t}+\epsilon_{i}+\mu_{i t}
$$

Or

$$
\text { Leverage }_{i t}=\beta_{o}+\beta_{1} \text { Logsale }_{i t}+\beta_{2} M T B_{i t}+\beta_{3} \text { Profitability }_{i t}+\beta_{4} \text { Tangibility }_{i t}+\omega_{i t}
$$

Where i denotes the cross-section index and t indicates the time index. $\epsilon_{i}$ is an firm-specific unobservable characteristic and $\mu_{i t}$ is a zero mean disturbance term. $\omega_{i t}$ is defined as

$$
\omega_{i t}=\epsilon_{i}+\mu_{i t}
$$

To determine whether there is a significant correlation between the firm effects and the explanatory variables, I utilized the Hausman specification test to determine whether it is more appropriate to use fixed or random effect model. In this case, random effect is preferred under the null hypothesis of correlation due to higher efficiency, while under the alternative. Fixed effects is at least consistent (whereas RE is not even consistent) and thus preferred, see Hausman (1978).

Additionally, to examine the effects of industry and time, I included the dummies in the base model as follows:

$$
\text { Leverage }_{i t}=\beta_{o i}+\sum \beta_{i} X_{i t}+D_{i} \beta_{o i D}+\sum D_{i} \beta_{i} D X_{i t}+D_{t}+\mu_{i t}
$$

Where $D_{i}$ and $D_{t}$ are the dummies for industry i and year t, respectively (to avoid the dummy variable trap, the number of industry and time dummies are the number of industries and years less 1).

Lastly, in recognition of the importance of size, I divided the sample to three groups based on the size of the firms and then examined the proposed hypotheses for each of the newly formed groups.

\section{Empirical Results}

This section presents my findings on the relationship between profitability of Vietnam listed firms and their leverage over the period of 2009-2013, covering the immediate aftermath of the Global financial crisis. Regression outputs for the models described in the methodology section are 
presented in Appendix 2 for ease of presentation. The primary results are also summarized in Table 6.

There are two 'stylized facts' of these regressions that are notably consistent throughout different specifications: first, the only variable that always has significant coefficient is profitability, and second, the intercept is always between 0.35 and 0.45 , meaning Vietnamese firms tend to keep a medium initial level of debt (about $40 \%$ of total asset) regardless of their characteristics.

First of all, I tried fitting the simplest (standard) fixed effect specification by controlling unobservable firm fixed effects. Using robust standard error estimates does not affect my results (See Table A1). Of the explanatory variables, only profitability and tangibility coefficients are statistically significant. Specifically, I observe a negative relationship between profitability and leverage: each percent gain in profitability decreases leverage by $0.372 \%$. Likewise, for each percent increase in tangibility we have a $0.322 \%$ increase in the ratio of debt to asset. On the other hand, size effect and value effect do not seem to have a big impact on the level of debt used by Vietnam firms.

This model is then compared with a random effect specification Table 6, with the only difference being the assumption of existing correlation between the cross-sectional errors and explanatory variables (so-called random effects). Here profitability still has a significant impact on leverage, with the coefficient decreasing slightly, implying a $0.4 \%$ leverage decrease per $1 \%$ increase of profitability. While market-to-book coefficient is still insignificant, now size coefficient has a positive, but not economically significant effect: $1 \%$ increase in size lead to $0.0097 \%$ increase in leverage. Tangibility, as well as M-B ratio, now has an insignificant impact on debt ratio.

The Hausman test results, as shown in Table 6, indicate that the null hypothesis of no correlation between regression errors and explanatory variables cannot be rejected, implying that the use of fixed-effect is more appropriate for this sample. This is expected since the cross-section variation is too systematic to be described by random effects.

Next, we include both firm-fixed effect and year fixed effect in one specification 6 . The year dummy variables basically control for factors that are exclusively related to time, which may affect all firms in our sample, such as a change/shock in macroeconomic policies or business environment. Compared to previous models, profitability coefficient's magnitude and sign do not change much. Interestingly, the other significant coefficient's place is now taken by M-B ratio; which is a positive $1.57 \%$ increase in leverage. The other two variables are now insignificant. Additionally, it seems that the year dummies capture important effect. Particularly, the difference between 2011, 2012 and 2013 compared with the base year (2009) is significant. During these years, Vietnam firms tended to increase their use of debt by $3.6 \%$ to $4.6 \%$ on average. This is in stark contrast with the argument that firms used less debt during these post-GFC years due to increasing financial constraints and capital controls exerted by both the government and the banking sector.

Table 6 then shows similar results when I replace firm effect by industry effect. Profitability's impact is still important and negatively related to leverage. However, the year effect is now no longer significant. This means that choices of debt level are actually affected by industrywide fluctuations more than country-wide changes in economic environment. In other words, the year effects are now absorbed by the variation of industries. Of these, the difference between all industries, except for 1002 and 1001, are significant and most of them are negative. Adding these differences to the intercept, I have a completely different picture from what I saw earlier: most firms in Vietnam, regardless of industries, adopt a very low level of debt, which is even negative level in some cases like $1004(-14.9+10.4=-4.5 \%)$ or $1005(-19.1+10.4=-8.7 \%)$. I can conclude that being in the property industry (1002) does not have a significant impact on the relative level of a firm's liabilities, nor does the aftermath of the GFC has a meaningful effect (on average) on these companies' financing behavior and profitability. This result goes against 
the common consensus stated in the motivation discussion, and thus constitutes strong evidence urging radical reconsideration of the role of primary sectors in Vietnam's financial instability.

The next table 6 presents results for the regression with industry dummies and corresponding interactions with profitability. With the base industry being wholesales and retails, the coefficient for profitability, MTB ratio and tangibility are now insignificant. Size effect sensitivity is now measured at $0.033 \%$. The difference between this industry and the $3,4,5,6,8,9$ are significant. Of these, only the 9th industry (construction) has greater sensitivity to profitability compared with the base industry, sitting at $(-0.0058+0.084=0.0782$, or $7.82 \%)$ leverage increase for $1 \%$ increase in ROA.

I can see that only profitability and size among all the determinants seem to have a persistent impact on leverage. It is, therefore, worthwhile to further examine the interaction between these two factors, by partitioning our sample into size groups and apply the OLS regression. I opted for categorizing our firms into large, medium and small firms based on their market value across years. Particularly, large firms have value greater than 1000 bilVND, medium firms have value between 300 bilVND and 1000 bilVND, and small firms are lower than 300 bilVND. These thresholds are suggested by the VN stock exchange management committee in deriving the VN-Index. The regression results for each of these firm groups are shown in Table 6. Overall, the sign and magnitude of the determinants are in agreement with established theories. Profitability's effect remains negatively significant for small and medium firms, while having no impact on large firms' debt level, thus confirming hypotheses H1a and H2a (specified in section 2). This is because large firms have access to alternative sources of funds other than debt whereas small and medium firms may be more financially constrained.

Table 6

Panel regression summary

\begin{tabular}{|c|c|c|c|c|c|}
\hline \multirow[b]{2}{*}{ Variables } & \multirow[b]{2}{*}{$\begin{array}{c}\text { Pooled OLS } \\
-1\end{array}$} & \multirow[b]{2}{*}{$\begin{array}{c}\text { Fixed effect } \\
-2\end{array}$} & \multirow[b]{2}{*}{$\begin{array}{c}\text { Random effect } \\
-3\end{array}$} & \multicolumn{2}{|c|}{ Industry and Time effect } \\
\hline & & & & $\begin{array}{c}\text { Without } \\
\text { interaction terms } \\
-4\end{array}$ & $\begin{array}{c}\text { With interaction } \\
\text { terms } \\
-5\end{array}$ \\
\hline Profitability & -0.012 & -0.004 & -0.004 & -0.010 & -0.006 \\
\hline p-value & 0.000 & 0.000 & 0.000 & 0.000 & 0.276 \\
\hline MTB & -0.015 & 0.005 & 0.003 & -0.006 & -0.008 \\
\hline $\mathrm{p}$-value & 0.010 & 0.378 & 0.298 & 0.344 & 0.193 \\
\hline Tangibility & -0.002 & -0.004 & 0.003 & 0.001 & 0.001 \\
\hline p-value & 0.669 & 0.000 & 0.212 & 0.778 & 0.681 \\
\hline Size & 0.033 & 0.005 & 0.010 & 0.033 & 0.033 \\
\hline p-value & 0.000 & 0.192 & 0.000 & 0.000 & 0.000 \\
\hline Adj. R-square & 0.090 & 0.023 & 0.020 & 0.212 & 0.220 \\
\hline No. of observations & & & 1238 & & \\
\hline F-stat & 30.73 & 31.38 & & 30.36 & 31.43 \\
\hline Wald-stat & & & 32.87 & & \\
\hline
\end{tabular}

In the end, it should be noted that I used the robust standard errors to calculate the statistics in all the regression models presented in this paper including cluster standard errors for random and fixed effect panel regression, and heteroscedasticity-robust standard error for Pooled OLS regression. Additionally, as a robustness check to ensure that the results are not sensitive to 
sample size, bootstrap procedure (random re sampling based on my sample data and replicate 1,000 times) was used to obtain bootstrap robust standard errors. The primary result, i.e. negative significant relationship between profitability and capital structure, is not changed, as can be seen in Table 6.

\section{Concluding Comments}

The main objective of the study was to examine the relationship between profitability and leverage. I found strong evidence of this relationship to be significantly negative. This relationship is not affected by other control variables as well as firm and year fixed effects. In particular, the results indicate that the smaller the firms are, the stronger the negative relationship is.

The various tests performed support the proposed hypotheses. After carrying out modifications to the base regression with different fixed effects and comparison with the random effect estimates, I can see that this relationship is insensitive to multiple changes in control conditions, among which the effects of firm size and industry are notable.

Consistent with many previous studies, the results are in favor of the Pecking order theory. Specifically, in the Vietnamese context, small and profitable firms tend to have higher incentive to use less debt. In contrast, large firms seem to be indifferent in their debt use due to having greater access to other sources of finance, as well as a larger base of collateral assets. Contrary to the arguments made in various official economic reports, Vietnam's firms operating in building and property industries do not seem to borrow significantly more than the other industries, even during the aftermath of the GFC when the government released its rescue package. I therefore advise more caution when interpreting previous studies implications on the impact of the GFC on; the property sector in particular, and other sectors in general, and its consequent effect on Vietnam's financial stability. Apparently there is more to this issue than the current consensus has suggested; which prompts further exploration in future. 


\section{References}

Akdal, S. (2011). How do firm characteristics affect capital structure? some uk evidence. Retrieved from https://papers.ssrn.com/sol3/papers.cfm?abstract _id $=1775706$

Banchuenvijit, W. (2012). Determinants of firm performance of Vietnam listed companies.

Barclay, M. J., \& Smith, C. W. (1999). The capital structure puzzle: Another look at the evidence. Journal of Applied Corporate Finance, 12(1), 8-20.

Baskin, J. (1989). An empirical investigation of the pecking order hypothesis. Financial Management, 18(1), 26-35.

Booth, L., Aivazian, V., Demirguc-Kunt, A., \& Maksimovic, V. (2001). Capital structures in developing countries. The Journal of Finance, 56(1), 87-130.

Chen, J. J. (2004). Determinants of capital structure of Chinese-listed companies. Journal of Business Research, 57(12), 1341-1351.

Gaud, P., Jani, E., Hoesli, M., \& Bender, A. (2005). The capital structure of Swiss companies: an empirical analysis using dynamic panel data. European Financial Management, $11(1), 51-69$.

Hamilton, R. T., \& Fox, M. A. (1998). The financing preferences of small firm owners. International Journal of Entrepreneurial Behavior \& Research, 4(3), 239-248.

Hausman, J. A. (1978). Specification tests in econometrics. Econometrica, 46 (6), 12511271.

Hol, S., \& Wijst, N. V. D. (2006). The financing structure of non-listed firms. Retrieved from https://brage.bibsys.no/xmlui//bitstream/handle/ 11250/180661/dp468.pdf?sequence=1\&isAllowed=y

International Monetary Fund. (2016). Vietnam: 2010 article iv consultation-staff report and public information notice. Retrieved from https://www.imf.org/external/ $\mathrm{pubs} / \mathrm{ft} / \mathrm{scr} / 2010 / \mathrm{cr} 10281 . \mathrm{pdf}$

Kraus, A., \& Litzenberger, R. H. (1973). A state-preference model of optimal financial leverage. The Journal of Finance, 28(4), 911-922.

Le, D. C. (2013). Determinants of capital structure decisions of Vietnamese financial managers. Journal of Development and Integration, 9(19), 22-28.

Le, T. K. T. (2012). An analysis of the determinants of capital structure of firms operating in the real estate sector listed on hose (Master Thesis, Da Nang University, Da Nang, Vietnam).

Miller, M. H., \& Modigliani, F. (1961). Dividend policy, growth, and the valuation of shares. Journal of Business, 34(4), 411-433.

Modigliani, F., \& Miller, M. H. (1958). The cost of capital, corporation finance and the theory of investment. The American Economic Review, 48(3), 261-297.

Munene, K. H. (2006). Impact of profitability on capital structure of companies listed at the Nairobi Stock Exchange (Doctoral dissertation). Retrieved from http:// erepository.uonbi.ac.ke/handle/11295/21966

Myers, S. C. (1984). The capital structure puzzle. The Journal of Finance, 39(3), 574-592.

Nguyen, T., \& Nguyen, H.-C. (2015). Capital Structure and Firms' Performance: Evidence from Vietnam's Stock Exchange. International Journal of Economics and Finance, 
$7(12), 1$

Nhung, L. T. P., \& Okuda, H. (2015). Effects of state ownership on companies' capital structure and profitability: Estimation analysis before and after the Lehman shock. Journal of Asian Economics, 38, 64-78.

Ojah, K., \& Manrique, J. (2005). Determinants of corporate debt structure in a privately dominated debt market: a study of the Spanish capital market. Applied Financial Economics, 15(7), 455-468.

Ozkan, A. (2001). Determinants of capital structure and adjustment to long run target: evidence from UK company panel data. Journal of Business Finance $\& 3$ Accounting, 28(1-2), 175-198.

Panno, A. (2003). An empirical investigation on the determinants of capital structure: the UK and Italian experience. Applied Financial Economics, 13(2), 97-112.

Qureshi, M. A. (2009). Does pecking order theory explain leverage behaviour in Pakistan? Applied Financial Economics, 19(17), 1365-1370.

Rajan, R. G., \& Zingales, L. (1995). What do we know about capital structure? some evidence from international data. The Journal of Finance, 50(5), 1421-1460.

Saliha, T., \& Abdessatar, A. (2011). The determinants of financial performance: an empirical test using the simultaneous equations method. Economics and Finance Review, 10(1), 1-19.

Serrasqueiro, Z., \& Nunes, P. M. (2010). Are trade-off and pecking order theories mutually exclusive in explaining capital structure decisions? African Journal of Business Management, 4(11), 2216-2228.

Titman, S. (1984). The effect of capital structure on a firm's liquidation decision. Journal of Financial Economics, 13(1), 137-151.

Wanrapee, B. (2011). Capital structure determinants of Thai listed Companies. In The clute institute international academic conferences (pp. 1-8).

Whittington, G. (1980). The profitability and size of United Kingdom companies, 1960-74. The Journal of Industrial Economics, 28(4), 335-352. 